\title{
Effect of an Evidence Based Protocol for Childhood Fever Management on Quality of Care Provided by Nurses Ghada M. Elseady ${ }^{1}$, Maha I. Khalifa ${ }^{2}$, Omayma M. Okby ${ }^{3}$, Neanaa M. Fayed $^{4}$ \\ ${ }^{1}$ Assistant Lecturer of Pediatric Nursing, ${ }^{2,3}$ Professor of Pediatric Nursing, ${ }^{4}$ Assistant professor of Pediatric Nursing, Faculty of Nursing, Menoufia University
}

\begin{abstract}
Background: Fever is a common childhood health problem. Meanwhile, nursing research suggests that management of children with fever is not based on updated scientific evidence. For this reason, Purpose of the study: To assess the effect of an evidence- based protocol for childhood fever management on quality of care provided by nurses. Setting: The study was conducted in Pediatric Medical Department and Pediatric intensive care unit in Menoufia University Hospital. Research design: A quasi experimental (pre and post) was utilized to conduct the study. Sample: All nurses (48 nurses) who were working in the previously mentioned settings were included in this study. Instruments: Two instruments were used. Instrument one was structured interviewing questionnaire. Instrument two was nurses' clinical performance observational checklist. Results: Nurses had higher mean of knowledge level about definition of fever on posttest compared to pretest (38.2 $\pm 2.8 \mathrm{Vs} 21.3 \pm 6.8$ ). Also, they had higher level of practices related to fever management on posttest than pretest $(45.1 \pm 2.1$ Vs 11.1 \pm 1.3 ) Conclusion: Implementation of an evidence- based protocol improved quality of care related to fever management. Recommendations: The study recommended that ongoing in-service education programs about evidence- based fever management must be designed and implemented in all pediatric departments and pediatric intensive care units to improve quality of care provided by nurses for children having fever.
\end{abstract}

Key words: Evidence based protocol, Childhood fever, Quality of care provided by nurses.

\section{Introduction}

Childhood fever is one of the most common clinical symptoms managed by pediatricians and other healthcare providers. It is considered the cause of nearly $65 \%$ of ambulatory pediatric visits. Feverish illness is very common in children with about $20 \%$ and $40 \%$ of parents reported fever in their children each year. So, the childhood fever is the second most common reason for a child being admitted to the hospital (Polat et al., 2014). However, nursing research suggests that management of children with fever is not based on upto-date scientific evidence (Chiappini et al., 2017).

Although, the incidence of serious infections has decreased after the introduction of conjugate vaccines, fever remains a major cause of laboratory investigation and hospital admissions (Barbi et al., 2017). Febrile illness in children usually indicates an underlying infection and is a cause of concern for parents and health care providers (Hu et al., 2016). The results of recent studies about the causes of fever showed similar findings, even though the distribution of diseases varies by geography, season, age, the immunity of the patient and the level of care (World Health Organization (WHO), 2013).

Fever in children can be a diagnostic challenge for health care professionals because it is often difficult to identify the cause. In most cases, the illness is due to a self- limiting viral infection. However, fever may also be the presenting feature of serious bacterial 


\section{Effect of an Evidence Based Protocol for Childhood Fever Management on Quality of Care Provided by Nurses}

infections such as meningitis or pneumonia. A significant number of children have no obvious cause of fever despite careful assessment. So, these children with fever without apparent source are of particular concern to health care professionals because, it is especially difficult to distinguish between simple viral illnesses and lifethreatening bacterial infections in this group. As a result, there is a perceived need to improve recognition, assessment and immediate treatment of feverish illness in children. Therefore, National Institute for Health and Clinical Excellence(NICE) developed traffic light system for predicting the risk of serious illness by assessing feverish children for the presence or absence of particular signs and symptoms (NICE, 2019).

Although, the disease process that leads to fever may be harmful, there is no evidence to demonstrate that fever itself is harmful. In fact, the presence of fever inhibits bacterial growth and the replication of viruses. Many children tolerate mild to moderate fever with remarkable ease. Fever has many immunological benefits, however, it is often viewed negatively by parents and nurses and treated aggressively (Greensmith, 2013).

Knowledge of fever management is inconsistent across studies from different countries. Incorrect beliefs among nurses toward fever and the role of antipyretics still exist. Knowledge deficit may be barriers to communicating or discussing nursing practices with doctors to provide better care for febrile children (Tran, 2014).

Nurses have a professional responsibility to promote and protect the safety and well-being of children. A key component of this is ensuring that children receive effective and evidence-based care. Pediatric nurses play a crucial role in the management of fever in children, being both the first responder to the detection of children with fever in the inpatient setting and an educator for the families of evidence- based best practices for fever management (Clark, 2019).

Evidence- based practice (EBP) is important for the professional development, responsibility and capabilities of the nurse. Consequently, it has become an important subject in nursing and has been integrated into daily nursing practices (Friesen-storms et al., 2015). Therefore, nurses whose practice is based on scientific evidence can make better decisions in services delivery (Stokke et al., 2014).

Evidence- based childhood fever management interventions should be targeted toward parents and health care providers. By adopting an evidencebased approach to nursing interventions, pediatric nurses can ensure that children receive appropriate and safe fever management (Kim, 2016). Therefore, evidence- based educational interventions for pediatric nurses need to be developed and evaluated to improve the quality of care in the management of fever. For this reason, the current study was implemented to assess the effect of an evidence- based protocol for childhood fever management on quality of care provided by nurses.

\section{Purpose}

The purpose of this study was to assess the effect of an evidence- based protocol for childhood fever management on quality of care provided by nurses.

\section{Research Hypothesis:}

1. Nurses who participate in an evidence- based protocol will have higher level of evidence- based knowledge related to fever on posttest than on pretest.

2. Quality of care provided by nurses for children having fever will be improved on posttest than on pretest.

\section{Methods}




\section{Effect of an Evidence Based Protocol for Childhood Fever Management on Quality of Care Provided by Nurses}

Research Design: A quasiexperimental design (pre and post-test) was utilized for this study.

Research Setting: This study was conducted in Pediatric Medical Department and Pediatric Intensive Care Unit in Menoufia University Hospital.

Sampling: All nurses providing care for children in Pediatric Medical Department and Pediatric Intensive Care Unit were involved in this study (48 nurses). The number of studied nurses at Pediatric Medical Department and Pediatric Intensive Care Unit in Menoufia University Hospital was 18 and 30 respectively.

Instruments:-

Two instruments were utilized for data collection:

Instrument one:

Structured

Interviewing

\section{Questionnaire:}

It is a structured interview questionnaire. It was developed by researchers guided by Walsh et al., (2005) after reviewing related literature. It was designed to collect data about nurses' social characteristics, knowledge about fever and its nursing care. It was consisting of three parts $(\mathrm{a}=0.951)$.

1. Part one: Social characteristics of studied nurses. It included questions about age, gender, level of education, years of experience and training courses.

2. Part two: Nurses' knowledge about fever. It included 21 items about definition of fever, normal range of body temperature, types of thermometers, methods of measuring temperature, benefits of fever and its complications, etc.

3. Part three: Nurses' knowledge about nursing care related to fever. It included 24 items about when to administer antipyretic drugs, route of administration, dosage of antipyretics, purpose of giving antipyretics, recommended water temperature for lukewarm bath, side effects and precautions for acetaminophen, etc.

The Total Scoring System of Nurses' Knowledge about Fever:

\begin{tabular}{|l|c|}
\hline Level of knowledge & Score \\
\hline Unsatisfactory $\leq 60 \%$ & $0-25$ \\
\hline Satisfactory > $00 \%$ & $26-42$ \\
\hline
\end{tabular}

The Total Scoring System of Nurses' Knowledge about Nursing Care related to Fever:

\begin{tabular}{|l|l|}
\hline Level of knowledge & Score \\
\hline Unsatisfactory $\leq 60 \%$ & $0-29$ \\
\hline Satisfactory $>60 \%$ & $30-48$ \\
\hline
\end{tabular}

Instrument two:

Nurses' Clinical Performance Observational Checklist: -

It was developed by researchers to observe nursing management of fever. It was divided into three parts $(\mathrm{a}=$ 0.921)

1. Part one: Immediate assessment on child admission. It included checking the child for immediate life-threatening signs, measuring child's body temperature and assessing child using traffic light system.

2. Part two: Management of children with fever. It included physical interventions and antipyretic interventions. Physical interventions included giving the child cooling drinks, keeping room ventilated, removing extra blankets and clothing, keeping child in light clothing, feeding if he or she is hungry and bathing child with lukewarm bath. Antipyretic interventions included evaluating children before medication and administering antipyretic medication if temperature is greater than $39^{\circ} \mathrm{C}$ and associated with discomfort.

3. Part three: Documentation and advice for home care. It included documentation of temperature, child's behavior, overall condition of the child and antipyretic administration. Advices for home care included giving regular fluids, monitoring for signs of dehydration, 


\section{Effect of an Evidence Based Protocol for Childhood Fever Management on \\ Quality of Care Provided by Nurses}

removing extra clothes, giving the child paracetamol only if he or she is distressed, keeping the child away from nursery or school, checking the child during night and when to seek further help.

The Total Scoring System of Nurses' Practices related to fever:

\begin{tabular}{|l|c|}
\hline Scoring items & Score \\
\hline Not Done $\leq 60 \%$ & $0-33$ \\
\hline Done $>60 \%$ & $34-53$ \\
\hline
\end{tabular} For validity assurance, the two
instruments were submitted to a jury of five experts in the Pediatric field (three professors in Pediatric Nursing and two professors in Pediatric Medicine) to modify any required items of the instruments. All required modifications were done.

\section{Ethical considerations}

Approval of the Faculty of Nursing in Menoufia Ethical Research Committee was obtained. A written consent was obtained from nurses related to their acceptance to share in the study after an initial interview was done to inform the nurses about the purpose and methods of data collection to gain their cooperation. They were assured that the information collected would be treated confidentiality and that it would be used only for the purpose of research. They informed that their participation in the study was voluntarily and the participants could withdraw from the study at any time.

\section{Pilot study :}

After the instruments were developed and before starting the data collection, a pilot study was carried out on $10 \%$ of the total sample (five nurses) to test the applicability, consistency, practicability, clarity and the feasibility of the study instruments and to estimate the needed time to fill the instruments. The results of the data obtained from the pilot study helped in the modification of the study instruments where some items were added as necessary. The researcher added steps of measuring child's body temperature using mercury glass thermometer. All nurses involved in the pilot study were excluded from the study sample.

\section{Procedure}

1. A written permission to carry out the study was obtained from the director of Menoufia University Hospital after submitting an official letter from the Dean of the Faculty of Nursing at Menoufia University explaining the purpose of the study and methods of data collection.

2. Data collection for this study was conducted for a period of 6 months extending from the first of January to the end of June 2020.

3. The researcher introduced herself to the nurses who participated in the study, explained the purpose of study and methods of data collection.

4. The researchers interviewed every nurse and asked her to fill the structured interviewing questionnaire about fever and its nursing care by using instrument one within 20 minutes (pretest).

5. Instrument two was used by the researchers for data collection about nurses' practices during providing care for children with fever. Nurses were not informed that they were observed three days per week during the morning and afternoon shifts (pretest).

6. Nurses were divided into ten groups to provide health education about evidence- based fever management. Each group contained five nurses. Each nurse received two health education sessions/week. Each session lasted for 90 minutes. The researchers conducted lectures, group discussion, demonstration \& re demonstration and distributed an explanatory related booklet. Sessions were conducted in Pediatric Intensive Care Unit and Pediatric Medical Department in Menoufia University Hospital.

7. The first session was about theoretical knowledge about evidence- based 


\section{Effect of an Evidence Based Protocol for Childhood Fever Management on Quality of Care Provided by Nurses}

knowledge related to fever such as normal range of temperature, definition of fever, thermoregulation, mechanisms of heat loss, types of thermometers, methods of measuring temperature, causes, signs and symptoms, benefits, management and complications. At the end of each session, the researchers answered nurses' questions, provided needed guidance and planned for future meeting.

8. The second session was about practical management of fever that is based on recent evidence. It included immediate assessment on child admission, management of fever (antipyretic interventions and physical interventions), documentation and advice for home care.

9. A post-test was done immediately following evidence- based protocol implementation to assess knowledge of nurses and observe their practices related to fever management by using instruments one and two.

10. A second post-test was done after 1 month following evidence- based protocol implementation to assess knowledge of nurses and observe their practices related to fever management by using instruments one and two.

\section{Statistical analysis:}

Data was coded and transformed into specially designed form to be suitable for computer entry process. Data was entered and analyzed by using SPSS (Statistical Package for Social Science) statistical package version 22. Graphics were done using Excel program.

Quantitative data was presented by mean $(\overline{\mathrm{x}})$ and standard deviation (SD). It was analyzed by using ANOVA (F) test for comparison between more than two means.

Qualitative data was presented in the form of frequency distribution, tables, number and percentage. It was analyzed by using chi-square $(\chi 2)$ test. However, if an excepted value of any cell in the table was less than 5, Fisher Exact test was used (if the table was 4 cells) or Likelihood Ratio (LR) test (if the table was more than 4 cells). Pearson correlation was used for explaining relationship between normally distributed quantitative variables.

\section{Results}

Table 1 showed that more than half of studied nurses $(58.3 \%)$ were $20-<30$ years with mean age $25.1 \pm 2.3$ years. Regarding gender of studied nurses, the majority of studied nurses $(85.4 \%)$ were female. In relation to nurses' qualifications, less than half of studied nurses $(45.8 \%)$ had nursing diploma. Regarding years of experience, less than half of studied nurses $(41.6 \%)$ had $>10$ years of experience. concerning training courses, the majority of studied nurses $(79.2 \%)$ did not attend any training courses on caring of children with fever.

Table 2 showed mean score of nurses' knowledge about fever in children on pre, post and follow-up tests. It was obvious that the mean and standard deviation of knowledge scores on pretest were $21.3 \pm 6.8$ compared to $38.2 \pm 2.8$ and $37.3 \pm 3.1$ on post and follow-up tests respectively. Therefore, there were very highly statistically significant differences between nurses' knowledge on pre, post and follow-up tests at 0.0001 level of statistical significance.

Table 3 showed mean score of nurses' knowledge about nursing care related to fever in children on pre, post and follow-up tests. As indicated in the table, the mean and standard deviation of knowledge score on pretest were $21.8 \pm 4.4$ compared to $39.1 \pm 2.2$ and $38.2 \pm 2.4$ on post and follow-up tests. Therefore, there were very highly statistically significant differences between nurses' knowledge on pre, post and follow-up tests at 0.0001 level 


\section{Effect of an Evidence Based Protocol for Childhood Fever Management on Quality of Care Provided by Nurses}

of statistical significance.

Table 4 illustrated distribution of nurses according to their total level of knowledge about fever and its nursing care on pre, post and follow-up tests. It was clear that all nurses had higher satisfactory knowledge on posttest compared to pretest $(100 \%$ Vs $35.4 \%$ respectively). Therefore, there were highly statistically significant differences between nurses' knowledge on pre, post and follow-up tests at 0.001 level of statistical significance.

Table 5 showed total mean scores of nurses' practices regarding fever in children on pre, post and follow-up tests. It was clear that nurses had higher mean score of practice on posttest compared to pretest $(45.1 \pm 2.1 \mathrm{Vs}$ $11.1 \pm 1.3$ respectively). Therefore, there were very highly statistical significant differences between nurses on pre, post and follow-up tests at 0.0001 level of statistical significance.

Figure 1 showed Pearson correlation between total score of nurses' knowledge and total score of nurses' practices of studied nurses. It reflected that there was a very highly significant positive correlation between total knowledge and total practices at 0.0001 level of statistical significance.

Table (1) Social characteristics of studied nurses $(n=48)$.

\begin{tabular}{|c|c|c|}
\hline Social characteristics of studied nurses & N0. & $\%$ \\
\hline $\begin{array}{l}\text { Age }(\text { Years }) \\
<20 \text { years } \\
20-<30 \\
30-<40 \\
\geq 40 \text { years }\end{array}$ & $\begin{array}{c}3 \\
28 \\
11 \\
6\end{array}$ & $\begin{array}{c}6.3 \\
58.3 \\
22.9 \\
12.5\end{array}$ \\
\hline Mean \pm SD & \multicolumn{2}{|c|}{$25.1 \pm 2.3$ years } \\
\hline $\begin{array}{l}\text { Gender: } \\
\text { Male } \\
\text { Female } \\
\end{array}$ & $\begin{array}{c}7 \\
41 \\
\end{array}$ & $\begin{array}{r}14.6 \\
85.4 \\
\end{array}$ \\
\hline $\begin{array}{l}\text { Qualification: } \\
\text { Nursing Diploma } \\
\text { Technical Institute of Nursing } \\
\text { Bachelor }\end{array}$ & $\begin{array}{c}22 \\
21 \\
5 \\
\end{array}$ & $\begin{array}{l}45.8 \\
43.8 \\
10.4 \\
\end{array}$ \\
\hline $\begin{array}{l}\text { Years of experience } \\
<1 \text { year } \\
1-<5 \text { years } \\
5-<10 \text { years } \\
\geq 10 \text { years }\end{array}$ & $\begin{array}{c}2 \\
13 \\
13 \\
20\end{array}$ & $\begin{array}{r}4.2 \\
27.1 \\
27.1 \\
41.6\end{array}$ \\
\hline $\begin{array}{l}\text { Training courses } \\
\text { No } \\
\text { Yes }\end{array}$ & $\begin{array}{l}38 \\
10\end{array}$ & $\begin{array}{l}79.2 \\
20.8\end{array}$ \\
\hline Total & 48 & 100 \\
\hline
\end{tabular}

Table (2): Mean Score of Nurses' knowledge about fever in children on pre, post and followup tests.

\begin{tabular}{|l|c|c|c|c|c|}
\hline Item & Pre test & Post-test & Follow -up test & Friedman test & P -value \\
\hline $\begin{array}{l}\text { Mean score of knowledge } \\
\text { about fever }\end{array}$ & $21.3 \pm 6.8$ & $38.2 \pm 2.8$ & $37.3 \pm 3.1$ & $\mathrm{~F}=16.7$ & $\mathrm{P}<0.0001$ \\
\hline
\end{tabular}

NB: P<0.0001: Means very highly statistical significance

F test: Analysis of variance for repeated measures for quantitative data

Table (3) Mean Score of Nurses' knowledge about nursing care related to fever in children on pre, post and follow-up tests.

\begin{tabular}{|l|c|c|c|c|c|}
\hline Item & Pre test & post test & Follow- up test & Friedman test & P -value \\
\hline Mean score & $21.8 \pm 4.4$ & $39.1 \pm 2.2$ & $38.2 \pm 2.4$ & $\mathrm{~F}=443.8$ & $\mathrm{P}<0.0001$ \\
\hline
\end{tabular}

NB: P<0.0001: Means very highly statistical significance.

F test: Analysis of variance for repeated measures for quantitative data. 


\section{Effect of an Evidence Based Protocol for Childhood Fever Management on Quality of Care \\ Provided by Nurses}

Table (4): Distribution of nurses according to their total level of knowledge about fever and its nursing care for children on pre, post and follow-up tests.

\begin{tabular}{|c|c|c|c|c|c|c|c|c|c|c|c|c|c|c|}
\hline \multirow[t]{2}{*}{ Items } & \multicolumn{4}{|c|}{$\begin{array}{c}\text { Pre- test } \\
n=48\end{array}$} & \multicolumn{4}{|c|}{$\begin{array}{c}\text { Post test } \\
n=48\end{array}$} & \multicolumn{4}{|c|}{$\begin{array}{c}\begin{array}{c}\text { Follow- up test } \\
n=48\end{array} \\
\end{array}$} & \multirow[b]{2}{*}{${ }_{2}^{*} \chi$} & \multirow[b]{2}{*}{$\begin{array}{c}P \\
\text { value }\end{array}$} \\
\hline & & (\%) & & ctory & $\begin{array}{l}\text { Uns } \\
\text { No }\end{array}$ & (\%) & $\begin{array}{l}\text { Sat } \\
\text { No } \\
\%\end{array}$ & $\begin{array}{l}\text { ctory } \\
\text {. }\end{array}$ & & (\%) & $\begin{array}{l}\text { Sat } \\
\text { No }\end{array}$ & $\begin{array}{l}\text { tory } \\
(\%)\end{array}$ & & \\
\hline $\begin{array}{l}\text { Total } \\
\text { knowledge } \\
\text { level }\end{array}$ & 31 & 64.6 & 17 & 35.4 & 0 & 0 & 48 & 100 & 0 & 0 & 48 & 100 & 79 & 0.000 \\
\hline
\end{tabular}

NB: $\quad$ P<0.001: Means highly statistical significance

${ }^{*} \chi 2$ : Repeated Friedman Test

Table (5): Total mean scores of nurses' practices regarding fever in children on pre, post and follow-up tests.

\begin{tabular}{|l|c|c|c|c|c|}
\hline Item & Pre test & Post-test & Follow -up test & Friedman test & P -value \\
\hline $\begin{array}{l}\text { Total Mean score of practice } \\
\text { about fever }\end{array}$ & $11.1 \pm 1.3$ & $45.1 \pm 2.1$ & $44.2 \pm 2.3$ & $\mathrm{~F}=4282$ & $\mathrm{P}<0.0001$ \\
\hline
\end{tabular}

NB: $\mathbf{P}<0.0001$ : Means very highly statistical significance

F test: Analysis of variance for repeated measures for quantitative data

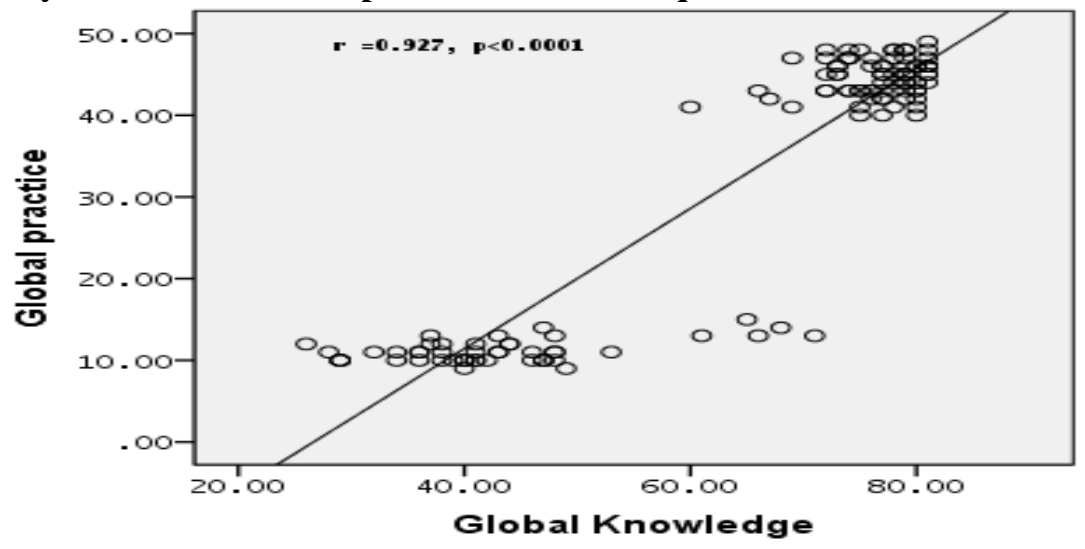

Figure (1): Pearson correlation between total score of nurses' knowledge and total score of nurses' practices of studied nurses $(n=48)$.

\section{DISCUSSION}

Fever management is a daily concern for pediatric nurses. So, pediatric nurses can play an important role by encouraging clinical research in this area and also by enhancing research utilization in their practice. Moreover, pediatric nurses can educate parents about evidence- based fever management. Evidence- based educational interventions for pediatric nurses need to be developed and evaluated to improve quality of care in the management of childhood fever (Jeong \& Kim, 2010).

The current study hypothesized that nurses who participate in evidencebased protocol will have higher level of evidence- based knowledge related to fever on posttest than on pretest. Also, quality of care provided by nurses for children having fever will be improved on posttest than on pretest.

Regarding mean score of nurses' knowledge about fever in children on pre, post and follow-up tests, the study illustrated that nurses had the highest level of knowledge on posttest. This was attributed to the effect of implementation of evidence- based protocol for childhood fever management. This could be attributed to the utilization of different educational strategies (presentations, group discussion and posters). This finding was in line with Vyas (2015) who conducted a study about "Knowledge and practice of staff nurses about nursing care of children 


\section{Effect of an Evidence Based Protocol for Childhood Fever Management on Quality of Care Provided by Nurses}

with fever" and he observed that the mean posttest knowledge score was higher than the mean pretest knowledge score. He concluded that the planned teaching program was effective in improving knowledge and practices of staff nurses.

Regarding mean score of nurses' knowledge about nursing care related to fever in children on pre, post and followup tests. As illustrated from the results, nurses had the highest mean level of knowledge on posttest. This can be attributed to the effect of training and instructions that were provided by the researchers. This result was in line with Wood et al., (2017) who conducted a study about "Evidence- based practices: Video discharge instructions in the pediatric emergency department." They found that Video Discharge Instructions (VDI) group achieved significantly higher scores on posttest than Written/ Verbal Discharge Instructions (SDI).

Furthermore, this result was consistent with Komeagac \& Bektas (2018) who conducted a study about "Effect of the evidence- based pediatric fever management training given to nursing students". They found a statistically significant difference between pretest and posttest and concluded that evidence- based training given to the nursing students on the management of pediatric fever increased the student's level of knowledge.

The present study showed that two thirds of nurses had unsatisfactory knowledge about fever and its nursing care on pretest. This finding agreed with Gouda et al., (2019) who conducted a study about 'Nurses' knowledge and practices regarding to fever management of neonates". They indicated that the majority of nurses had unsatisfactory knowledge regarding to fever management of neonates. This might be due to the absence of in-service training programs about fever management and the absence of formal hospital policies for fever management.
Also, this finding agreed with Greensmith (2013) who conducted a study about 'Nurses' knowledge and attitudes toward fever and fever management in one Irish Hospital". The study identified that pediatric nurses were not expert fever managers and their knowledge deficits as well as their negative attitudes influenced their practices. In addition, it was also, recommended that continuing education was needed to ensure the latest clear evidence available in the literature for best practice in fever management was applied.

Regarding mean scores of total nurses' practices about fever in children on pre, post and follow-up tests, the results illustrated that nurses had higher mean score of practices on posttest than on pretest. This could be due to the effectiveness of an evidence- based protocol for childhood fever management. This finding was consistent with Gouda et al., (2019) who conducted a study about "Nursing management of fever in neonatal intensive care units". They found that there was a marked improvement on posttest with highly statistically significant difference. As well, Jeong \& Kim (2015) who conducted a study about "Childhood fever management program for Korean pediatric nurses" and found that two different training programs received by nurses encouraged evidence- based nursing practices and improved the quality of childhood fever management.

Concerning correlation between total knowledge and total practices, the present study reflected that there was a very highly statistically significant positive correlation between total knowledge and total practices. This finding agreed with Gouda (2018) who conducted a study about "Nurses' knowledge and practices regarding to fever management of neonates" and reported that there was a statistically significant difference between total knowledge and total practice levels of 


\section{Effect of an Evidence Based Protocol for Childhood Fever Management on \\ Quality of Care Provided by Nurses \\ References}

studied nurses. Also, this finding came in line with Abou Zaid (2014) who conducted a study about "Improving the quality of nursing care for neonates receiving total parenteral nutrition". $\mathrm{He}$ found that there was a statistically significant difference between total knowledge and total practice of the studied nurses. As well, Hegazy (2014) conducted a study about "Nurses' knowledge versus their performance in caring for neonates having respiratory distress syndrome". He found that there was a statistically significant difference between total knowledge and total practice levels of the studied nurses.

\section{CONCLUSION}

Based on the findings of the present study, it was concluded that nurses who participated in an evidence- based protocol had higher level of evidencebased knowledge related to fever management on posttest than pretest. Quality of care provided by nurses for children having fever was improved after implementation of the evidence- based protocol (posttest) than on pretest.

\section{Recommendations}

Based on the conclusion of the present study, the following recommendations can be suggested:

1. Ongoing in-service education programs about evidence- based childhood fever management should be designed and implemented in pediatric department and pediatric intensive care units to improve nurses' knowledge and practices.

2. Standardized evidence- based protocols for childhood fever should be integrated into pediatric nursing curriculum and implemented in pediatric departments .

3. Future studies should be applied on a larger sample of nurses in other pediatric medical departments to investigate the effect of evidencebased protocol for childhood fever management on quality of care provided by nurses to ensure the generalizability of results.
Abou-zaid, S. (2014): Improving the quality of nursing care for neonates receiving total parenteral nutrition. MD. Thesis, Faculty of nursing. Ain Shams University.

Barbi, E., Marzuillo, P., Neri, E., Naviglio, S., \& Krauss, B. S. (2017). Fever in Children. Pearls and Pitfalls, 4(9),81. https://doi.org/10.3390/children40900 81.

Chiappini, E., Venturini, E., Remaschi, G., Principi, N., Longhi, R., Tovo, P. A., .. \& de Martino, M. (2017). 2016 update of the Italian pediatric society guidelines for Management of Fever in children. The Journal of pediatrics, 180,177-183.

https://doi.org/10.1016/j.jpeds.2016.0 9.043 .

Clark, S. (2019). Management of Fever in Children: Realities of Nursing Practice. Doctoral dissertation. The University of Auckland. https://researchspace.auckland.ac.nz/d ocs/uoa-dcs/rights.htm.

Friesen-Storms, J. H., Moser, A., van der Loo, S., Beurskens, A. J., \& Bours, G. J. (2015). Systematic implementation of evidence-based practice in a clinical nursing setting: A participatory action research project. Journal of clinical nursing, 24(1-2), 57-68.

Gouda, S. S. (2018). Evidence based practice for nursing management of fever in neonatal intensive care units. Doctoral thesis. Faculty of Nursing. Ani Shams University. http:// www.eul.edu.eg.

Gouda, S. S., Ouda, W. E., Adly, R. M. \& Tantawi, H. R. (2019). Nursing management of fever in neonatal intensive care units: Evidence-based practice. International journal of Novel Research in Health Care and 


\section{Effect of an Evidence Based Protocol for Childhood Fever Management on \\ Quality of Care Provided by Nurses}

Nursing,6(1), 277-285. Available at www.novelty journals.com.

Gouda, S. S., Ouda, W. E., Adly, R. M. \& Tantawi, H. R. (2019). Nurses' knowledge and practices regarding to fever management of neonates. Egyptian Journal of Healrh Care ,3(3), 31-40.

Greensmith, L. (2013). Nurses' knowledge of and attitudes toward fever and fever management in one Irish children's hospital. Journal of Child Health Care, 17(3).305-316.

Hegazy, A. (2014): Nurses' knowledge versus their performance in caring for neonates having respiratory distress syndrome MD. Thesis, Faculty of nursing. Ain Shams University, 153179.

Hu, F., Zhang, J., Shi, S., \& Zhou, Z. (2016). Fever management in the emergency department of the Children's Hospital of Fudan University. A best practices implementation project, JBI Database of Systematic Reviews and Implementation Reports, 14(9), 358366.

https://doi.otg/10.11124/JBISRIR2016-003072.

Jeong Y. \& Kim J. (2015). Childhood fever management program for Korean pediatric nurses: A comparison between blended and face-to-face learning method. Contemporary Nurse, 49(1), 35-46.

Jeong, Y. S., \& Kim, J. S. (2010). Fever and fever management in children: A literature review. Child Health Nursing Research,16(1),30-40. https://doi.org/10.4094/jkachn.2010.16.1.30.

Kim, J. S. (2016). Childhood fever management: Current practice vs evidence. Child Health Nursing Research,22(2),126-136. https://doi.org/10.40994/chnr2016.22.2.126.

Komeagac, A., \& Bektas, M. (2018). Effect of the evidence-based pediatric fever management training given to nursing students. International Journal of Caring Sciences, 11(2), 860-867.

National Institute for Health and Care Excellence (NICE). (2019). Fever in under 5s: Assessment and initial management. (UK); (NICE Guideline, No. 143). http://www.ncbi.nlm. nih/books/NBK552086/.

Polat, M., Kara, S., Tezer, H., Tapısız, A., Derinöz, O., \& Dolgun, A. (2014). A current analysis of caregivers' approaches to fever and antipyretic usage. The Journal of Infection in Developing Countries, 8(03), 365371 . https://dio.org/ 10.3855/jidc.3904.

Stokke, K., Olsen, N. R., Espehaug, B., \& Nortvedt, M. W. (2014). Evidence based practice beliefs and implementation among nurses: a cross-sectional study. BMC nursing, 13(1), 1-10.

Tran, T. K. L. (2014). Fever management in children: Vietnamese parents' and pediatric nurses' knowledge, beliefs and practices. Doctoral dissertation, Queensland University of Technology.

Vyas, D.Y. (2015). Knowledge and practice of staff nurses about nursing care of children with fever. $J$ lab and life Scs,1(2), 17-26, eISSN 24550930.

Wood, E. B., Harrison, G., Trickey, A., Friesen, M. A., Stinson, S., Rovelli, E., ... \& Presgrave, K. (2017). Evidence-based practice: videodischarge instructions in the pediatric emergency department. Journal of Emergency Nursing, 43(4), 316-321. https://doi/org/10.1016/j.jen.2016.11. 00 .

World Health Organization [WHO]. (2013). Informal Consultation on Fever Management in Peripheral Health Care Settings: A Global Review of Evidence and Practices. ISBN 9789241506489. 